\title{
Knowledge, Attitudes, and Practice Related to Pap Smear Test among Iranian Women
}

\author{
Fatemeh Mousavi ${ }^{1}$, Parisa Shojaei ${ }^{1^{*}}$ and Hoda Aryan ${ }^{2}$ \\ ${ }^{1}$ Department of Community \& Preventive Medicine, Social Determinants of Health Research \\ Center, Tehran Medical Science Branch, Islamic Azad University, Tehran, Iran \\ ${ }^{2}$ Medical Student, Tehran Medical Sciences Branch, Islamic Azad University, Tehran, Iran
}

*Corresponding author: Parisa Shojaei, Department of Community \& Preventive Medicine, Social Determinants of Health Research Center, Tehran Medical Science Branch, Islamic Azad University, Tehran, Iran

\begin{abstract}
The Pap smear is a reliable, inexpensive and effective screening test for cervical cancer; the second most common cancer among women worldwide. We aimed to determine women's knowledge, attitudes and practice towards Pap smear in women live at the northwest of Tehran city. This study, was carried out on 334 outpatient Iranian women in winter 2018. A questionnaire including demographic characteristics (10 questions), knowledge (10 questions), attitudes (5 questions) and practice (2 questions) towards Pap smear was completed by an interview with the women. The data were analyzed using SPSS ver22. The mean age of all participants was $36.59 \pm 15.409$ years. $52.4 \%$ had performed the Pap smear test, $24.3 \%$ of which performed Pap smears regularly the knowledge level of participants who had done Pap smear was low at $28.6 \%$, moderate at $55.4 \%$, and high at $16.0 \%$. The knowledge level of participants who did not perform Pap smear was low at $41.5 \%$, moderate at $49.7 \%$, and high at $8.8 \%$. The attitude of the participants to Pap smear was undesirable in $1.2 \%$, moderate in $3 \%$, and $98.8 \%$ desirable. The attitude of the participants who had done Pap smear was undesired in $4.2 \%$ of the subject, moderate in 15\%, and desired in 80.8 and in another group was $15.5 \%, 56.7 \%$ and $27.8 \%$ respectively. The knowledge and practice of the women were inadequate and needed to be promoted. Considering the main reason mentioned by the participants for not having the test, all health providers should educate and encourage women to do regular Pap smear.
\end{abstract}

\section{Keywords}

Pap smear, Knowledge, Attitudes, Practice, Iranian women

\section{Introduction}

Cervical cancer is the most common cancer and the main cause of death in women in developing countries. Based on the World Health Organization (WHO), 22\% of female deaths are caused by malignant tumors, which $18 \%$ of them are due to cervical cancer [1]. Based on WHO prediction, the number of cancer cases in developing countries will be 0.7 million by 2020 [2]. It is the second most common cancer in the world leading to the death of women $[3,4]$. The prevalence of cancer among women in the world is 1 per 10 people, and one person loses her life due to cervical cancer every 2 minutes [5]. Approximately one million women every year have advanced cervical cancer worldwide, and $50 \%$ of cases cause death. In 2009, the National Program of Cancer Registry in Iran Ministry of Health and Medical Education reported a prevalence of 1.17 cases per 100,000 people for cervical cancer [6]. In Iran, this cancer is one of the most common cancers among women, and it is the third cause of death after heart disease and accidents $[1,7]$. Its prevalence and mortality is $2.2 \%$ and $1 \%$, respectively, in Iran [8]. Its major risk factors include sexual intercourse under age 18 years, multiple sexual partners, and previous history of sexually transmitted infections $[9,10]$. Several conventional methods have been proposed for the early diagnosis of cervical cancer and its secondary prevention, which Pap smear is the most effective method for screening of cervical cancer and no technique better than this method has

Citation: Mousavi F, Shojaei P, Aryan H (2018) Knowledge, Attitudes, and Practice Related to Pap Smear Test among Iranian Women. Int J Womens Health Wellness 4:076. doi.org/10.23937/24741353/1510076

Accepted: August 22, 2018: Published: August 24, 2018

Copyright: (c) 2018 Mousavi F, et al. This is an open-access article distributed under the terms of the Creative Commons Attribution License, which permits unrestricted use, distribution, and reproduction in any medium, provided the original author and source are credited. 
been observed so far for prevention of cervical cancer $[11,12]$. The American Cancer Society in 2002 recommended annual screening by Pap smear test for women, and the American College of Obstetricians and Gynecologists recommends annual screening for women aged less than 30 years. It also recommends increasing the screening intervals for 2-3 years for women aged over 30 years, who have no symptom of this disease. However, studies show that $20 \%$ of US women are not unfortunately screened regularly and they have not undergone Pap smear over the past three years [4]. Pap smear is a simple, inexpensive, painless, and relatively reliable screening method for diagnosis of cervical cancer and infection [11] and search for finding the pre-cancer changes in patients, which has been successful in reducing the incidence of cervical cancer by up to $79 \%$ and in reducing mortality by up to $70 \%$ [4]. This method can diagnose the pre-cancer lesions for 10 to 20 years or more before cancer development $[11,13]$. The difference observed between developed and developing countries in mortality caused by cervical cancer might relate to performing or non-performing Pap smear, and various studies have shown the relationship between mortality reduction and Pap smear screening program [14]. Early diagnosis and prevention are suitable for screening test due to the long pre-invasive period $[4,15]$. Knowledge is one of the most important factors predicting the health behaviors and an effective factor in performing screening methods. However, knowledge alone is not adequate, since individual's attitude is also an important factor in preventive behaviors and the cancer control without a positive attitude will not be successful [16]. Most women do not use this test regularly, as recommended by the health communities $[13,17]$. Given the past studies conducted in this regard, a large number of women still do not have adequate knowledge about this diagnostic method. There is currently no mass screening program for early detection of similar cancers in most low-income and middle-income countries (LMICs), and cancer screening policies in Iran are opportunistic. Therefore, the only people who are aware of the importance of these tests include screening of cancer in their health plans [18]. There are limited number of studies on knowledge, attitude and practice of women about Pap smear in the country [19]. Hence, this study was conducted to evaluate the knowledge, attitude, and practice of Pap smear among Iranian women at Tehran.

\section{Method}

This cross-sectional study was performed on women who attended clinics, at the northwest of Tehran, Iran in 2018.

\section{Participants}

Considering $p=27 \%$ for having Pap smear at least once (based on results of a study by Soltanahmadi, et al. [20], $d=0.05$, and a significant level of $95 \%, 302$ sample was required for the study (Appendix 1 ). Inclusion crite- ria were: married; lack of speech and hearing problems; lack of history of any cancer. A total of 334 Iranian women were selected from women who visited the clinics in northwest of Tehran and have medical record in this clinic. Time frame for identifying women through the medical records is 5 days and for recruiting study participants was 6 days. 512 women were identified through review of medical records that $65.23 \%$ of women have tended to participate in the study and Completed informed consent.

\section{Data collection}

The study participants were selected through sequential sampling method. Data were collected via face-to-face interviews with one trained interviewer using a self-administrated questionnaire. The questionnaire included 9 questions about participants background information (age, age of marriage, educational level, marital status, place of living, insurance coverage, number of pregnancies, read or heard of cervical cancer, source of information) 10 questions to assess the level of knowledge, 5 questions related to attitudes towards Pap smear, and 2 questions focused on the behavior and practice of the participants include: 1) Have you ever done Pap smear, 2) Do you do it frequently. Answers to the questions were with the two options "yes" and "no". The knowledge questions were completed by only those who had heard about the Pap smear, while the attitude statements by all of the subjects (those who had heard and not heard about the Pap smear). For those who claimed to have not heard something about Pap smears, before bringing up the attitude questions, the researcher explained briefly about Pap smear (i.e., Pap smear detects cervical cancer. It is taken after placement of women in lithotomy position and insertion of a speculum into vagina, and then the specimen is sent to the pathology lab). Content validity of the questionnaire was determined using the comments of 5 experts including gynecologists and midwifery faculty members and its reliability using test-re-test. Knowledge questions had three options. To calculate knowledge and attitude score, correct answers were given score 1, and incorrect answers were given score 0 . To produce a total knowledge and attitudes score, the scores were summed 0-10. A higher score reflects a higher knowledge or better attitudes about Pap smear. The total knowledge and attitude score was classified into three level; scores 0-3.99 "weak", scores of 4-6.99 level of "medium" and a score of 7 or higher level of "good".

\section{Data analysis}

Data were analyzed by using SPSS 25 . The Chi-square test was used to assess the association between two qualitative variables. The multiple logistic regression analysis was used to estimate the risk of different factors for the practice of Pap smear test. The independent variables: age, education level, place of living, job, mari- 
Table 1: Background information of respondents.

\begin{tabular}{|c|c|c|}
\hline Characteristics & $\begin{array}{l}\text { Having had Pap } \\
\text { smear }(n=175)\end{array}$ & $\begin{array}{l}\text { Not having had Pap } \\
\text { smear }(n=159)\end{array}$ \\
\hline Age, y & $44.95 \pm 13.10$ & $27.69 \pm 12.68$ \\
\hline Age of marriage, $y$ & $21.36 \pm 4.09$ & $20.31 \pm 4.28$ \\
\hline $\begin{array}{l}\text { Number of } \\
\text { pregnancies }\end{array}$ & $2.26 \pm 1.16$ & $0.92 \pm 1.65$ \\
\hline \multicolumn{3}{|l|}{ Marital status } \\
\hline Single & $10(5.7 \%)$ & $115(72.3 \%)$ \\
\hline Married & $144(82.2 \%)$ & $38(23.9 \%)$ \\
\hline Separate \& Divorce & $14(8.0 \%)$ & $1(0.6 \%)$ \\
\hline Widow & $7(4.0 \%)$ & $5(3.1 \%)$ \\
\hline \multicolumn{3}{|l|}{ Occupation } \\
\hline Medical & $35(20.0 \%)$ & $67(42.1 \%)$ \\
\hline Non-medical & $140(80.0 \%)$ & 92 (57.9\%) \\
\hline \multicolumn{3}{|l|}{ Educational level } \\
\hline $\begin{array}{l}\text { Under high school } \\
\text { graduated }\end{array}$ & $22(12.6)$ & $14(8.8)$ \\
\hline $\begin{array}{l}\text { High school } \\
\text { graduated }\end{array}$ & $60(34.3 \%)$ & 30 (18.9\%) \\
\hline $\begin{array}{l}\text { graduated } \\
\text { University Degree }\end{array}$ & $93(53.1 \%)$ & $115(72.3 \%)$ \\
\hline \multicolumn{3}{|l|}{ Health insurance } \\
\hline No & $14(8.2 \%)$ & $14(8.8 \%)$ \\
\hline Yes & $161(91.8 \%)$ & $145(91.2 \%)$ \\
\hline \multicolumn{3}{|l|}{ Place of living } \\
\hline Tehran & $165(94.3 \%)$ & $146(91.8 \%)$ \\
\hline Out of Tehran & $10(5.7 \%)$ & $13(8.2 \%)$ \\
\hline \multicolumn{3}{|l|}{$\begin{array}{l}\text { Source of } \\
\text { information }\end{array}$} \\
\hline $\begin{array}{l}\text { Family and } \\
\text { Acquaintance }\end{array}$ & $32(18.3 \%)$ & $44(27.7 \%)$ \\
\hline Gynecologist & 77 (44.0\%) & $34(21.4 \%)$ \\
\hline Other physicians & $9(5.1 \%)$ & $11(6.9 \%)$ \\
\hline Midwives & $16(9.1 \%)$ & $7(4.4 \%)$ \\
\hline Media & $57(32.6 \%)$ & $68(42.8 \%)$ \\
\hline \multicolumn{3}{|l|}{$\begin{array}{l}\text { Read or heard of } \\
\text { cervical cancer }\end{array}$} \\
\hline Yes & $150(85.7 \%)$ & $111(69.8 \%)$ \\
\hline No & $25(14.3 \%)$ & $48(30.2 \%)$ \\
\hline
\end{tabular}

tal status, the age of marriage, parity, health insurance, read or heard of cervical cancer and source of information about of Pap smear were included in the model to control for confounding. The adjusted odds ratios and their $95 \% \mathrm{Cl}$ for associated factors are reported. Also, the data was presented as mean \pm SD.

\section{Results}

The sociodemographic characteristics of the 334 studied women are presented in two groups (Having had Pap smear, not having had Pap smear) in Table 1. The most of subjects in two groups had University Degree, live in Tehran, non-medical job and have health insurance. Moreover, our results indicate that among women, most of them in two groups obtained their information from media. The knowledge level of participants who had done Pap smear was low at $28.6 \%$, moderate at $55.4 \%$, and high at $16.0 \%$. The knowledge level of participants who did not perform Pap smear was low at $41.5 \%$, moderate at $49.7 \%$, and high at $8.8 \%$. The most frequent $(56.0 \%)$ participant's knowledge in group who did not perform Pap smear about risk factor of breast cancer was high-risk partners. In another group, multiple partner $(55.4 \%)$ was risk factor of breast cancer. The attitude of the participants who had done Pap smear was undesired in $4.2 \%$ of the subject, moderate in $15 \%$, and desired in 80.8 and in another group was $15.5 \%, 56.7 \%$ and $27.8 \%$ respectively. Table 2 show the questions regarding knowledge, attitude and practice of two group participants about Pap smear. The highest and lowest corrected respond to knowledge of two groups were related to "Do you know about Pap smear test" and "Do you know Pap smear is for screening which cancers", respectively. Our results indicated that $85.7 \%$ of participants who had done Pap smear read or heard about Pap smear that this percentage was lower in the second group (69.8\%). Most of the participants who had done Pap smear (90.9\%) was agreed with Pap smear as a screening for cervical cancer, and among the disagreed of them, most reasons for not performing Pap smear, was reported not accessible. In participants who did not perform Pap smear, $75.5 \%$ was agree and among the disagreed of them, most reasons for not performing was husband's disapproval. Among participants in two groups that was agreed with Pap smear, prefer to take it governmental Health care centers and done by gynecologist. Out of 334 participants, $52.4 \%$ performed the Pap smear test, $24.3 \%$ of which performed Pap smear test frequently, indicating that parity could be problematic for a person. There was no significant relationship between age and gravid with knowledge ( $P>0.05$ ). However, marriage age had a significant relationship with knowledge $(P=0.004)$. There was no significant relationship between age, the age of marriage and gravid with attitude $(P>0.005)$. The age of marriage have not a significant relationship with performing the Pap smear (practice 1) $(P>0.05)$, but had significant relationship with performing Pap smear frequently (practice 2$)(P=$ $0.0001)$. Higher age was associated with performing the Pap smear $(P=0.034)$ but have not a significant relationship with performing Pap smear frequently $(P>0.05)$. Gravid have not a significant relationship with performing the Pap smear and frequently (Table 3 ). According to logistic regression (Table 4), age, education level, insurance coverage, knowledge and attitude were significant factors with performing Pap smear, which means that the probability of having a Pap smear was higher more than 1.081 times with increase in age, more than 0.265 times with an increase in education level, more than 2.241 times with improved source of information, more than 1.224 times with increasing knowledge and 1.245 times improve attitudes. In practice 2, with increasing educational level (0.483 times) and knowledge (1.221 times), regular Pap smear increases among the subjects.

\section{Discussion}

Knowledge, attitude, and practice of the community 
Table 2: Knowledge, attitudes and practice regarding Pap smear screening among studied women.

\begin{tabular}{|c|c|c|c|c|}
\hline & \multicolumn{2}{|c|}{ Having had Pap smear $(n=175)$} & \multicolumn{2}{|c|}{ Not having had Pap smear $(n=159)$} \\
\hline & No & Yes & No & Yes \\
\hline & $N(\%)$ & $\mathrm{N}(\%)$ & $\mathrm{N}(\%)$ & $N(\%)$ \\
\hline \multicolumn{5}{|l|}{ Knowledge } \\
\hline \multicolumn{5}{|l|}{ 1. Risk factors for cervical cancer: } \\
\hline Risk factors for cervical cancer: Marriage in low age & $140(80)$ & $35(20)$ & $127(79.9)$ & $32(20.1)$ \\
\hline $\begin{array}{l}\text { Risk factors for cervical cancer: First pregnancy in } \\
\text { low age }\end{array}$ & $151(86.3)$ & $24(13.7)$ & $142(89.3)$ & $17(10.7)$ \\
\hline Risk factors of cervical cancer: Multiple partners & $78(44.6)$ & $97(55.4)$ & $89(56.0)$ & $70(44.0)$ \\
\hline Risk factors for cervical cancer: High-risk partners & $83(47.4)$ & $92(52.6)$ & $70(44.0)$ & $89(56.0)$ \\
\hline $\begin{array}{l}\text { Risk factors of cervical cancer: Alcohol consumption } \\
\& \text { Smoking }\end{array}$ & $118(67.4)$ & $57(32.6)$ & $120(75.5)$ & $39(24.5)$ \\
\hline Risk factors of cervical cancer: STDs & $95(54.3)$ & $80(45.7)$ & $91(57.2)$ & $68(42.8)$ \\
\hline $\begin{array}{l}\text { Risk factors for cervical cancer: Multiple gestations } \\
\text { with small intervals }\end{array}$ & $145(82.9)$ & $30(17.1)$ & $134(84.3)$ & $25(15.7)$ \\
\hline $\begin{array}{l}\text { Risk factors for cervical cancer: low personal } \\
\text { hygiene }\end{array}$ & $92(52.6)$ & $83(47.4)$ & $87(54.7)$ & $72(45.3)$ \\
\hline Risk factors for cervical cancer: low socio-economic & $129(73.7)$ & $46(26.3)$ & $126(79.2)$ & $33(20.8)$ \\
\hline 2. Do you know about Pap smear test & $12(6.9)$ & $163(93.1)$ & $69(43.4)$ & $90(56.6)$ \\
\hline $\begin{array}{l}\text { 3. Do you know Pap smear is for screening which } \\
\text { cancers }\end{array}$ & $165(94.3)$ & $10(5.7)$ & $146(91.8)$ & $13(8.2)$ \\
\hline 4. Is early diagnosis of cervix cancer possible & $36(20.6)$ & $139(79.4)$ & $49(30.8)$ & $110(69.2)$ \\
\hline 5. Does early diagnosis result in better prognosis & $31(17.7)$ & $144(82.3)$ & $45(28.3)$ & $114(71.7)$ \\
\hline 6. Does Pap smear finds lesions with no signs & $64(36.6)$ & $111(63.4)$ & $85(53.5)$ & $74(46.5)$ \\
\hline $\begin{array}{l}\text { 7. Do you know women must do Pap smear } 3 \text { years } \\
\text { after first intercourse }\end{array}$ & $84(48.0)$ & $91(52.0)$ & $94(59.1)$ & $65(40.9)$ \\
\hline $\begin{array}{l}\text { 8. Do you know women must do Pap smear } \\
\text { annually till } 30 \text { y/o }\end{array}$ & $72(41.1)$ & $103(58.9)$ & $100(62.9)$ & $59(37.1)$ \\
\hline $\begin{array}{l}\text { 9. Do you know women over } 30 \text { y/o must do Pap } \\
\text { smear at least each } 3 \text { years }\end{array}$ & $81(46.3)$ & $94(53.7)$ & $104(65.4)$ & $55(34.6)$ \\
\hline $\begin{array}{l}\text { 10. Does women must inhibit coitus the day before } \\
\text { the test }\end{array}$ & $97(55.4)$ & $78(44.6)$ & $113(71.1)$ & $46(28.9)$ \\
\hline \multicolumn{5}{|l|}{ Attitude } \\
\hline 1. Do you agree with Cancer screenings & $15(8.6)$ & $160(91.4)$ & $37(23.3)$ & $122(76.7)$ \\
\hline $\begin{array}{l}\text { 2. Do you agree with Pap smear as a screening for } \\
\text { cervix cancer }\end{array}$ & $16(9.1)$ & $159(90.9)$ & $39(24.5)$ & $120(75.5)$ \\
\hline \multicolumn{5}{|l|}{ 3. If you Disagree, what is your reason? } \\
\hline Painful & $2(12.5)$ & $14(87.5)$ & $0(0.0)$ & $39(100)$ \\
\hline Shame & $2(12.5)$ & $14(87.5)$ & $2(5.1)$ & $37(94.9)$ \\
\hline Husband's Disapproval & $2(12.5)$ & $14(87.5)$ & $0(0.0)$ & $39(100)$ \\
\hline No physicians' recommendation & $1(6.3)$ & $15(93.8)$ & $6(15.4)$ & $33(84.6)$ \\
\hline Not accessible & $0(0)$ & $16(100)$ & $4(10.3)$ & $35(89.7)$ \\
\hline Not affordable & $5(31.3)$ & $11(68.8)$ & $3(7.7)$ & $36(92.3)$ \\
\hline Fear of positive findings & $2(12.5)$ & $14(87.5)$ & $6(15.4)$ & $33(84.6)$ \\
\hline Being Busy & $2(12.5)$ & $14(87.5)$ & $8(20.5)$ & $31(79.5)$ \\
\hline \multicolumn{5}{|l|}{ 4. If you Agree, where you prefer to take it } \\
\hline Governmental Gynecology clinics in Hospital & $59(37.10)$ & $100(62.90)$ & $22(18.33)$ & $98(81.67)$ \\
\hline Governmental Health care centers & $32(20.12)$ & $127(89.88)$ & $9(7.5)$ & $111(92.5)$ \\
\hline Private Clinics & $113(71.06)$ & $46(28.94)$ & $83(69.16)$ & $37(30.84)$ \\
\hline \multicolumn{5}{|l|}{ 5. If you Agree, Prefer to be done by who } \\
\hline Family Medicine Physician & $55(34.59)$ & $104(65.41)$ & $50(41.66)$ & $70(58.34)$ \\
\hline Gynecologist & $22(13.83)$ & $137(86.17)$ & $19(15.83)$ & $101(84.17)$ \\
\hline Midwifes & $98(61.63)$ & $61(38.37)$ & $38(31.66)$ & 82 (68.34) \\
\hline
\end{tabular}

about any disease and its factors offer a crucial opportunity for comprehensive prevention and control strategies of the disease. Therefore, this study addressed knowledge, attitude and practiced about Pap smear as an entry point for the prevention and control of cervical cancer and its associated factors among women. The knowledge level of participants in this study was moder- ate in two groups that did and did not performing Pap smear. In accordance to our findings, Moreir, et al. reported that the knowledge of participant was moderate [21]. In several studies, knowledge as the well as practice among the women were low [12,17,19,22-25]. Ilter, et al. also revealed that the studied women had a high knowledge of Pap smear test (82\%) [25]. However, de- 
Table 3: Association of the knowledge, attitude, and practice regarding Pap smear test with sociodemographic characteristics.

\begin{tabular}{|c|c|c|c|c|c|c|c|c|}
\hline \multirow[t]{2}{*}{ Characteristics } & \multicolumn{2}{|c|}{ Knowledge } & \multicolumn{2}{|c|}{ Attitude } & \multicolumn{2}{|c|}{ Practice1 } & \multicolumn{2}{|c|}{ Practice2 } \\
\hline & $X 2$ & p value & $\mathbf{X} 2$ & $p$ value & $\mathrm{X} 2$ & p value & $\mathbf{X} 2$ & $p$ value \\
\hline $\begin{array}{l}\text { Marital status } \\
\text { Single } \\
\text { Married } \\
\text { Separate \& Divorce } \\
\text { Widow }\end{array}$ & 18.550 & 0.005 & 4.612 & 0.594 & 6.034 & 0.110 & 9.310 & 0.025 \\
\hline $\begin{array}{l}\text { Occupation } \\
\text { Medical } \\
\text { Non-medical }\end{array}$ & 1.145 & 0.001 & 1.145 & 0.564 & 0.332 & 0.791 & 0.149 & 0.819 \\
\hline $\begin{array}{l}\text { Educational level } \\
\text { Under high school graduated } \\
\text { High school graduated } \\
\text { University Degree }\end{array}$ & 29.004 & 0.000 & 2.672 & 0.849 & 1.540 & 0.673 & 8.300 & 0.040 \\
\hline $\begin{array}{l}\text { Health insurance } \\
\text { No } \\
\text { Yes }\end{array}$ & 1.754 & 0.416 & 8.015 & 0.018 & 0.438 & 0.552 & 6.351 & 0.012 \\
\hline $\begin{array}{l}\text { Place of living } \\
\text { Tehran } \\
\text { Out of Tehran }\end{array}$ & 16.447 & 0.000 & 1.088 & 0.580 & 1.729 & 0.191 & 6.413 & 0.011 \\
\hline $\begin{array}{l}\text { Source of information } \\
\text { Family and Acquaintance } \\
\text { Gynecologist } \\
\text { Other physicians } \\
\text { Midwives } \\
\text { Media }\end{array}$ & 25.905 & 0.001 & 8.449 & 0.391 & 5.053 & 0.282 & 10.573 & 0.032 \\
\hline
\end{tabular}

Practice 1: Have you ever done Pap smear; Practice 2: Do you do it frequently.

Table 4: Significant factors associated with the practice of Pap smear test among studied women as estimated by the multiple logistic regression analysis ${ }^{1}$.

\begin{tabular}{|c|c|c|c|c|}
\hline \multirow[t]{2}{*}{ Factor } & \multirow{2}{*}{$\begin{array}{l}\text { Odds ratio } \\
\text { (adjusted) }\end{array}$} & \multicolumn{2}{|c|}{$95 \%$ C. 12} & \multirow[t]{2}{*}{ p-value } \\
\hline & & Lower & Upper & \\
\hline \multicolumn{5}{|c|}{ Practice 1: Have you ever done Pap smear } \\
\hline Age & 1.081 & 1.012 & 1.155 & 0.020 \\
\hline Educational level & 0.265 & 1.050 & 2.281 & 0.015 \\
\hline Marriage & 0.450 & 0.027 & 7.568 & 0.579 \\
\hline Age of marriage & 0.920 & 0.830 & 1.109 & 0.236 \\
\hline Occupation & 1.002 & 0.217 & 4.628 & 0.947 \\
\hline Place of living & 2.639 & 0.419 & 16.626 & 0.301 \\
\hline Health insurance & 2.218 & 0.356 & 13.825 & 0.012 \\
\hline Number of pregnancies & 0.682 & 0.365 & 1.275 & 0.231 \\
\hline Source of information & 2.241 & 0.707 & 7.097 & 0.170 \\
\hline Knowledge & 1.224 & 1.033 & 1.452 & 0.020 \\
\hline Attitude & 1.355 & 1.044 & 1.759 & 0.022 \\
\hline \multicolumn{5}{|c|}{ Practice 2: Do you do it frequently } \\
\hline Age & 1.027 & 0.982 & 1.074 & 0.237 \\
\hline Educational level & 0.483 & 1.108 & 2.154 & 0.024 \\
\hline Marriage & 1.411 & 0.153 & 2.214 & 0.163 \\
\hline Age of marriage & 1.052 & 0.937 & 1.182 & 0.393 \\
\hline Occupation & 2.314 & 0.744 & 7.190 & 0.147 \\
\hline Place of living & 2.317 & 0.212 & 25.328 & 0.491 \\
\hline Health insurance & 0.762 & 0.075 & 2.258 & 0.999 \\
\hline Number of pregnancies & 0.786 & 0.473 & 1.228 & 0.265 \\
\hline Source of information & 0.721 & 1.252 & 2.064 & 0.011 \\
\hline Knowledge & 1.221 & 1.077 & 1.385 & 0.002 \\
\hline Attitude & 1.245 & 0.968 & 1.603 & 0.088 \\
\hline
\end{tabular}

${ }^{1}$ The variables age, education level, place of living, occupational status, marital status, the age of marriage, number of pregnancies, health insurance, source of information about of Pap smear, knowledge and attitude were included in the model as independent variables. $95 \% \mathrm{Cl} 2=95 \%$ confidence interval for adjusted odds ratio. spite the high level of knowledge, participants never performed a Pap smear test, so they showed lower practice compared to subjects of other studies. In the study conducted by Rezaie-Chamani, et al. the results showed that less than half of the women had heard about Pap smear, and 25\% of women had Pap smear at least once [19]. In the present study, more information about Pap smear was obtained from media. So, given that the primary source for women was media, it has to work to improve the credibility of the information that comes through the media. It also provided information that is not limited to a specific group of people and is in harmony with the culture and education level of the community to encourage the whole community to promote its health and community. This finding is consistent with the study by Almobarak, et al. [26]. According to result of Haroon and Bakheit (2004) study, the major source of information have been delivered through the gynecological doctor which indicate that the primary care physician has no role in providing the information about cervical cancer and its detection by the Pap smear screening [27]. In our study most of the women in two groups had ever heard about the cervical cancer screening test that is similar to those reported for Singapore, Vietnamese-American women, and South Asian women living in the New York City area [28], but lower when compared with those reported for developed countries and some developing countries such as Argentina and Brazil $[14,29]$. The differences in the above studies could be due to different population's involved and different levels of intervention such as existing population-based screening programs, or mass media campaigns to popu- 
larize cervical screening [30]. In our study, there was a significant relationship between knowledge and occupational status, marital status, information source, education level, residence, and marriage age. Indeed, people with medical occupations will certainly have a higher level of knowledge than other people due to the consistent acquisition of relevant information. Married people also tried to gain more knowledge due to their greater need for this test and knowledge level was significantly lower among widows. According to our expectations, women with higher education level have a higher knowledge level, but having higher education did not affect their attitudes. Residence in Tehran due to access a variety of information resources, increase the knowledge level. As the age of marriage increases because of the need for women to prevent and control cervical cancer, they are trying to improve their knowledge of this issue. Similar results were found by Arevian who report that education is the most important predictor of knowledge about Pap smear test even once in their life [31]. In our study, the attitude of women who had done Pap smear was favorable, which was consistent with the study of Mutambar, et al. [32]. In our study attitude of the most participants was desired that indicating the tendency and willingness of population towards this issue. Therefore, given the high motivation of women to perform Pap smear, if more people are aware of this test, a large number of women will do this test. Women who did not perform Pap smear had moderate attitude. Therefore, this group needs more attention and reinforcement of the attitude towards doing this test. In our study, the main reasons among participants who had done Pap smear and disagreed with Pap smear as a screening for cervical cancer include not accessible and for participants who did not perform Pap smear was husband's disapproval. That is, if the problem of accessing the test is resolved among these people, they will all attempt to do this. However, among those who have not done this test, husband's disapproval is a great obstacle that need to educating and justifying their husbands before or along with women's education, to participate in this important work and health of their wives. In a study conducted by Mutambara, et al. in Zimbabwe [32], it was found that more women believed that Pap smear test was fearful and painful. In the Moreira, et al. study, the main reasons for women not to be tested for Pap smear were embarrassment and fear of pain [21]. The main reason given for not having had a Pap smear was that it was not suggested by the doctor (48.4\%), which was similar to the studies from South Africa [33], among Vietnamese American women [34] and Argentina [14]. Other important reasons which included embarrassment, fear of infection, fear of discovery of cancer and no symptoms, misconception about the test being painful have also been reported in other studies in different proportions $[10,35]$. In a study conducted by Alavi, et al. in 2010 , only $18.8 \%$ of gynecologist and ob- stetrician specialists performed Pap smear annually, and 295 of them did not perform this test even once. The main reasons for not performing Pap smear test were negligence and lack of willingness to be examined by colleagues [36]. Regarding questions about "where you prefer to take it" and "Prefer to be done by who", the results showed that most of participants in two groups preferred to perform Pap smear by gynecologist and in governmental Health care centers. This finding suggests that women tend to refer to a specialist in the first step and performed Pap smear by gynecologist. In other words, if they want to do it, they prefer to do Pap smear by gynecologist in governmental centers with low cost. So the cost of doing this test was very important for our subjects. The rate of Pap smear taking was observed to this study is $52.4 \%$ and $24.3 \%$ done regularly. The rate of Pap smear taking was observed to be varying in the different developed and developing countries, and this has significantly affected the reported prevalence of cancer in different countries. Different rates of Pap smear testing was reported in various studies; e.g., $20 \%$ in Kenya, $40.3 \%$ in Jordan, $69 \%$ in Spain, 93\% in the United States of America and $28.9 \%$ in Turkey [26]. In our study, some of the participants have already performed Pap smear, but fewer of them performed it alternately. In several study [21,37] was found that many women given the poor practice of about half of the subjects in performing Pap smear test and the positive attitude of most of subjects towards performing Pap smear. seems that providing solutions to enhance the knowledge level of subjects in order to enhance the practice of women to be an essential. In our study, the only influential variable on women's attitudes was insurance coverage. In other words, women will improve their attitude towards this test after gaining the necessary knowledge if they have insurance coverage, and the costs are the high priority for them. But in Abedian and Dormohamadi [37] study there was a significant relationship between knowledge, attitude, and practice with age, and no significant relationship between knowledge, attitude and practice with education level. According to our results, there was a significant relationship between regular performing of Pap smear and marital status, the source of information, education level, place of residence, age at marriage, and having insurance. Therefore, it can be stated that married women tend to have more regular Pap smear and were significantly less in widows. Perhaps these people feel that they do not have to test it regularly due to the loss of their husbands and lack of sexual activity. The type of information source also depended on the regular performing of Pap smear, and in those who get information from a gynecologist, they are more likely to be required to do this because they receive this information from a specialist in the same field. Another logical consequence was that women with higher education at university level were expected to do it regularly due to a better 
knowledge of this issue. Women living in Tehran are more likely to follow this test due to access to facilities and public and private centers more than those outside Tehran. Meanwhile, with the increase in the age of marriage, women are more likely to be at risk of cervical cancer, and they are therefore regularly monitored. If the age of the marriage did not affect the first time performing, Pap smear test was effective, but the age of the affected women was higher, and the mean age was higher in women who performed the test for the first time. Women's insurance coverage is also not effective when tested for the first time, but spend cost for performing regular Pap smear was an important issue. While they do not do it regularly if they have not insurance coverage. Therefore, the widespread insurance coverage of this test for most women in the community can be one of the most important motivating factors for its regular performing that leads to improving the health of women and society. However, only age had a meaningful relationship with Pap smear, and with the increase in mean age, the desire of participants to perform Pap smear increased. Furthermore, physicians and patients usually behave differently in response to illness level according to the patient's age, which makes it less likely to ask for the test in younger age group women unless symptomatic. The fact that many young women in the 20-29 years age group had not taken the test may be due to the low background risk for cervical cancer in the country [22]. In a study conducted by Albuquerque, et al. in Brazil (2010), a significant correlation was found between performing Pap smear and marital status, number of children, the age of subjects, and level of education and frequency of visit to gynecologist [29]. In Almobarak, et al. study, the average age was higher among women who took Pap smear test, and these women had more gynecological examinations, lived in the City Centre, had a higher socioeconomic level as well as higher level of knowledge about Pap smear test and higher education level [26]. Our study identified the level of education and knowledge were significant factor independently associated with practice about doing and frequently doing Pap smear test when adjusted for the effect of other factors in multivariate logistic regression analysis. Knowledge and attitude are the two most interlinked domains for prevention and control of cervical cancer Women who had never received information about the disease from any source were more likely not to undergo the screening. In this study, as a commentary on the role of the media in informing, the cultural and religious roots of society should be taken into account. It seems that informing about issues such as Pap smear should be done by other methods that are consistent with our community culture.

\section{Acknowledgement}

This study was conducted by the Social Medicine Department of Islamic Azad University of Medical Sciences of Tehran. The author thanks medical interns of the social medicine rotation.

\section{Declaration of Conflicting Interests}

The authors declare that they have no conflicts of interest.

\section{References}

1. Alam M M-AS (2006) Knowledge, attitude and practice of home health care workers in the province Pap smear. J Hormozgan Univ Med Sci.

2. Parkin DM, Bray F (2006) Chapter 2: The burden of HPV-related cancers. Vaccine 24: S3/11-25.

3. Parkin DM, Bray F, Ferlay J, Pisani P (2005) Global cancer statistics, 2002. CA Cancer J Clin 55: 74-108.

4. Garcia FHK, Berek JS (2015) Intraepithelial disease of the cervix, vagina, and vulva. In: Berek JS, Berek \& Novak's gynecology. (15 th edn), Philadelphia: Lippincott Williams \& Wilkins.

5. Society AC. Cancer Facts and Figures.

6. Malmir S, Barati M, Jeihooni AK, Bashirian S, Hazavehei SMM (2018) Effect of an educational intervention based on protection motivation theory on preventing cervical cancer among marginalized women in West Iran. Asian Pac J Cancer Prev 19: 755-761.

7. Majidi A, Majidi S, Salimzadeh S, Khazaee- Pool M, Sadjadi A, et al. (2017) Cancer screening awareness and practice in a middle income country: A systematic review from Iran. Asian Pac J Cancer Prev 18: 3187-3194.

8. Ferlay J, Shin HR, Bray F, Forman D, Mathers C, et al. (2010) Estimates of worldwide burden of cancer in 2008: GLOBOCAN 2008. Int J Cancer 127: 2893-2917.

9. Anorlu RI (2008) Cervical cancer: The sub-Saharan African perspective. Reprod Health Matters 16: 41-49.

10. Bener A, Denic S, Alwash R (2001) Screening for cervical cancer among Arab women. Int J Gynaecol Obstet 74: 305-307.

11. Mirzakhani K JSN (2005) Cervical cancer screening and Pap smear. Sokhangostar 65-71.

12. Getahun F, Mazengia F, Abuhay M, Birhanu Z (2013) Comprehensive knowledge about cervical cancer is low among women in Northwest Ethiopia. BMC Cancer 13: 2.

13. Mutyaba T, Mmiro FA, Weiderpass E (2006) Knowledge, attitudes and practices on cervical cancer screening among the medical workers of Mulago Hospital, Uganda. BMC Med Educ 6: 13.

14. Gamarra CJ, Paz EP, Griep RH (2005) [Knowledge, attitudes and practice related to Papanicolaou smear test among Argentina's women]. Rev Saude Publica 39: 270-276.

15. Giuntoli RL BR (2008) Cervical cancer. In: Gibbs RS, Karlan BY, Haney AF, Nygaard I, Danfoth's Obstetrics and Gynecology. (10 th edn), Philadelphia: Lippincott Williams \& Wilkins.

16. Abedzadeh M, Sadat Z, Saberi F (2003) Knowledge, attitude, and performance of women referring health care centers in Kashan towards breast cancer and its screening tests. Feyz J 7: 85-92.

17. Belete N, Tsige Y, Mellie H (2015) Willingness and acceptability of cervical cancer screening among women living with HIVIAIDS in Addis Ababa, Ethiopia: A cross sectional study. Gynecol Oncol Res Pract 2: 6. 
18. Adab P, McGhee SM, Yanova J, Wong CM, Hedley AJ (2004) Effectiveness and efficiency of opportunistic cervical cancer screening: Comparison with organized screening. Med Care 42: 600-609.

19. Rezaie-Chamani S, Mohammad-Alizadeh-Charandabi S, Kamalifard M (2012) Knowledge, attitudes and practice about pap smear among women reffering to a public hospital. Journal of Family and Reproductive Health 6: 177-182.

20. Soltanahmadi Z, Abbaszadeh A, Tirgari B (2010) A survey on the rate and causes of women's participation or nonparticipation in breast and cervical cancers screening programs. The Iranian Journal of Obstetrics, Gynecology and Infertility 13: 37-46.

21. Moreira ED Jr, Oliveira BG, Ferraz FM, Costa S, Costa Filho JO, et al. (2006) Knowledge and attitudes about human papillomavirus, Pap smears, and cervical cancer among young women in Brazil: Implications for health education and prevention. Int J Gynecol Cancer 16: 599-603.

22. Aweke YH, Ayanto SY, Ersado TL (2017) Knowledge, attitude and practice for cervical cancer prevention and contro among women of childbearing age in Hossana Town, Hadiya zone, Southern Ethiopia: Community-based cross-sectional study. PLoS One 12: e0181415.

23. Wright K, Aiyedehin O, Akinyinka M, llozumba O (2014) Cervical cancer: Community perception and preventive practices in an urban neighborhood of Lagos (Nigeria). ISRN Preventive Medicine 2014.

24. Waiswa A, Nsubuga R, Muwasi M, Kimera I, Ndikabona G, et al. (2017) Knowledge and attitude towards cervical cancer screening among females attending out patient Department in Health Centre IIIs in Oyam District. Open Journal of Preventive Medicine 7: 55-62.

25. Ilter E, Celik A, Haliloglu B, Unlugedik E, Midi A, et al (2010) Women's knowledge of Pap smear test and human papillomavirus: Acceptance of HPV vaccination to themselves and their daughters in an Islamic society. Int J Gynecol Cancer 20: 1058-1062.

26. Almobarak AO, Elbadawi AA, Elmadhoun WM, Elhoweris $\mathrm{MH}$, Ahmed $\mathrm{MH}$ (2016) Knowledge, attitudes and practices of Sudanese women regarding the pap smear test and cervical cancer. Asian Pac J Cancer Prev 17: 625-630.
27. Bakheit NM, Haroon AIB (2004) The knowledge, attitude and practice of pap smear among local school teachers in Sharjah district. Middle East J Fam Med 4: 10-18.

28. Al Sairafi M, Mohamed FA (2009) Knowledge, attitudes, and practice related to cervical cancer screening among Kuwaiti women. Med Princ Pract 18: 35-42.

29. Albuquerque CLFd, Costa MdP, Nunes FM, Freitas RWJ, Azevedo PRM, et al. (2014) Knowledge, attitudes and practices regarding the Pap test among women in northeastern Brazil. Sao Paulo Med J 132: 3-9.

30. Curry SJ, Byers T, Hewitt M (2003) Improving Participation in Cancer Screening Programs.

31. Arevian M, Noureddine S, Kabakian T (1997) A survey of knowledge attitude and practice of cervical screening among Lebanese/Armenian women. Nurs Outlook 45: 16-22.

32. Mutambara J, Mutandwa P, Mahapa M, Chirasha V, Nkiwane S, et al. (2017) Knowledge, attitudes and practices of cervical cancer screening among women who attend traditional churches in Zimbabwe. Journal of Cancer Research and Practice 4: 53-58.

33. Wellensiek N, Moodley M, Moodley J, Nkwanyana N (2002) Knowledge of cervical cancer screening and use of cervical screening facilities among women from various socioeconomic backgrounds in Durban, Kwazulu Natal, South Africa. Int J Gynecol Cancer 12: 376-382.

34. Nguyen TT, McPhee SJ, Nguyen T, Lam T, Mock J (2002) Predictors of cervical Pap smear screening awareness, intention, and receipt among Vietnamese-American women. Am J Prev Med 23: 207-214.

35. Maaita M, Barakat M (2002) Jordanian women's attitudes towards cervical screening and cervical cancer. J Obstet Gynaecol 22: 421-422.

36. Alavi Gh HJ, Fattahi Masoom AS, Taghi Shakeri M (2010) Evaluation of prevalence of cervical and breast cancer screening programs between gynecologists. Iran J Obstet Gynecol Infertil 1-6.

37. Abedian Z, Dormohamadi M (2013) investigating awareness, attitude and practice of women who referred to Health Centers of Mashhad City toward pop smear. The Iranian Journal of Obstetrics, Gynecology and Infertility 15: 22-28.

\section{Appendix 1}

$$
\begin{aligned}
& n=\frac{\left(Z_{1-\frac{\alpha}{2}}\right)^{2} p(1-p)}{d^{2}} \\
& n=\frac{(1.96)^{2} \times 0.27 \times 0.73}{0.05 \times 0.05}=302
\end{aligned}
$$

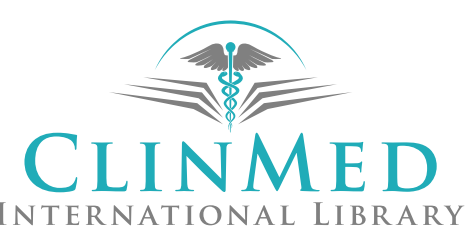

